apparently losing sight of the fact that no advocate of the open method advocates the introduction of Eepsis.

No modern surgeon of to.day will deny that practioaliy all tractures of the patella and of the olecranon should, under proper precantions, be subjected to the open method of treatment. In the face of euch statistics as I have quoted, can any one deny the advantage of the open method for most fractures of the femur?

Then we come to the leg. When either the tibia or fibula is broken usually there is not much displacement, and the one bone serves a useful falcrum whereby the broken ends may be brought into good position. Under such circumstances, therefore, it fi $\theta$ quently is not necessary to do the open operation. When, however, we $\operatorname{com} \theta$ to a fracture of both bones, with a de. formity that cannot be overcome, or to a Pott's, with the tearing of the internal malleolus and its associated lacer. ation of the annular ligament, with d is place ment forward of the tendon of the tibialis pos. ticus, I think

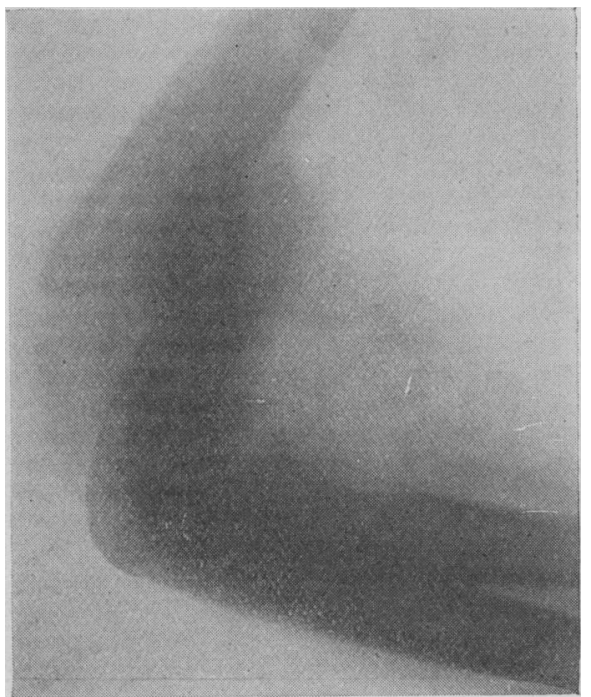

Fig. 5.-Compound comminuted fracture of the lower end of humerus. the open metbod is imperative, in view of the $\epsilon$ dd.results in fracture of both bones of the leg exanined in from one and a half to ten years after.

Out of 35 cases in the Massachusetts General Hospita], 13 cases reported the injured leg "as good as the other" 22 cases showed a leg permanently impaired, some with deformity, some with flat feet, etc.

About one good result out of every three cases treated; I really think it time for some change in method.

In all fractures implicating a joint-with the possible exception of fracture of the neck of the femur-surely patients will prefer the risk of the open operation, done with proper precantions, to the certainty of permanent crippling.

In the space of time at my disposal it is quite out of the question for me to go into detuil in all classes of fractures, and some I am omitting, for example, depressed fracture of the skall, and fractures of the spine giving rise to pressure symptoms, for in these there can be no two npinions as to the proper procedure, for even a LucasChampionnière or a Sir William Bennett would be unable to elevate the depressed fragments by massage.

Having spoken of the risks, I shall briefly outline some of the advantages to be gained by the open method:

1. The mechanism of the skeleton is left unimpsired, and the patient therefore has a perfect anatomical and functional result.

2. The period of incapacity is shortened.

3. The pain is relieved in a few hours.

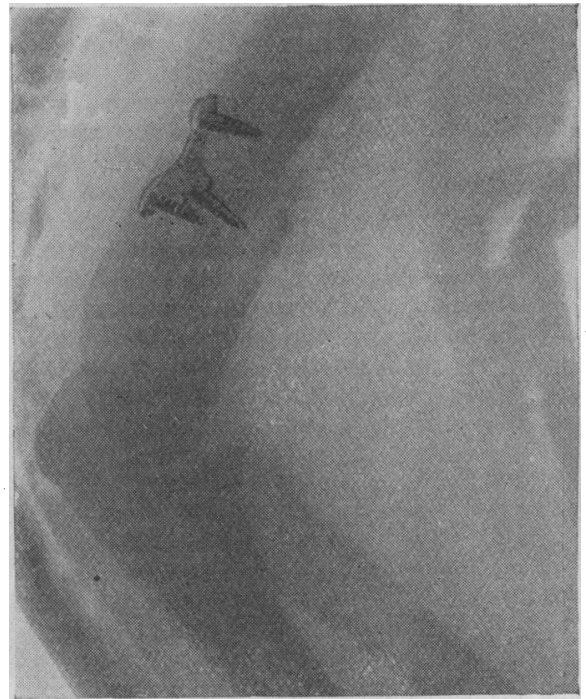

4. There is no risk of muscle fibre being left between the bones to favour non.union.

5. The sur. geon can see what be is doing and c a n accurately ap. proximate the frag. ments.

6. $T h \theta r \theta$ is immediate relief from the tension, otc, from extravasation.

In $1903 \mathrm{I}$

Fig. 6. The same after plating. This patient was able to leave the hospital on his bicycle read a paper o $n$ "T h. e. Open Method of Treating Fractures' ${ }^{9}$ before this Association, and it seems. to me a propriate that I should contribute to the same Association any further light that I bave found upon the subject after a prolonged and painstaking study of all the methods now in vogue, on a large series of cases, both in private and hospital practice. I am more convinced than ever, as a result of my observations, that there are now many cripples going about our streets who might have had a perfect skeletal mechanism had the open method bees adopted.

REFERENCES.

1 Clinical 5ournal, October 7th, 1908. 2 Practitioner, February, 1909: Treatise on Fractures, Malgaigne. A Annals of Surgery, November, 1908 or The 6 Annals of Surgery. Heath and Selby, January, 1908. 7 BRIrIsH MEDICAL JodRNaL. October 6th, 1900. 8 Scudder's Treatment of Fractures, 1:07. 9 Canadian Sournal of Medicine and 'Surgery. January, 1907.

\title{
ACCURACY IN THE DIAGNOSIS OF URINARY DISEASE.*
}

By BERNARD J. WARD, F.R.C.S.

SURAEON TO OUT-PATIENTS TO THE QUEEN'S AND TO THE CHIIDREN'S HOSPITALS, BIRMINGEAM.

ThE difficulties met with in attempting a diagnosis from the symptomatology of urinary disease may be grouped under three main headings:

1. The symptoms of the various diseases which affect a particular part of the urinary tract often mimic one another so closely as to render their differential diagnosis difficult.

2. Reflex or transferred symptoms may throw suspicion on the wrong part of the tract.

3. The very absence of symptoms in certain cases, whose only complaint is the passage of blood or pus in the urine, makes it difficult to localize the site of the lesion.

Let us consider more in detail each of these difficulties.

* Abstract of a paper read before the Worcester Branch of the British Medical Association.

\section{Difficulties of Diagnosis.} A.-Due to Mimicry.

It has been the custom for years past to look upon suche a group of symptoms as increased frequency of micturition, pain at the end of the penis after micturition, and the passage of blood in the urine towards the end of micturition, all perhaps made worse by exercise, as pathognomonic of a stone in the bladder. Now this group of symptoms is. the immediate expression of cystitis and the symptoms are due to an inflammation of the bladder mucous membrane.

The pain is caused by the muscular wall of the bladder contracting down on and squeezing its inflamed and Eens $i$ tive lining, and is therefore worst when the bladder is empty and contracted.

The blood in the urine at the end of micturition is explained as follows : The veins from the mucous membrane of the bladder run between the muscular fibres of its walp to reach the large venous plexuses situated outside, so that when these muscular fibres contract the veins are compressed and the tension of the blood within them is raised, and if their walls are thinned by ulceration or are only 
feebly supported like those of a villous growth, they give way and bleeding results. This also occurs towards the end of mictarition when the muscular fibres are most tightly contracted and therefore produce the greatest amount of obstruction to the flow of blood through the veins.

The increased frequency of micturition is accounted for by the lessened distensibility of the bladder owing to the inflammatory infiltration of its mucous membrane, so that the call to urinate occurs more frequently than normal. This latter fact is often of use in practice, for from the knowledge of how often a patient passes his urine a very accurate idea may be formed of how much lotion his bladder will hold. A satisfactory cystoscopic examination cannot be made with a distension of less than $6 \mathrm{oz}$.

All diseases of the bladder sooner or later cause cystitis, and as inflammation is a necessary part of most diseases of this viscus, the symptoms of cystitis-pain, frequency, and blood-will mask those due to the individual disease. Such diverse diseases of the bladder as stone, cystitis, ulceration simple or taberculous, growths, and even in flammatory affections of the prostate, often cause identical symptoms. The routine use of the cystoscope has im pressed this very strongly on me during the last fow years.

CASE I.

A few weeks ago I saw a child, who had twice had his bladder opened suprapubically by two different surgeons for the group of symptoms we are now considering. Both expected to find a stone, but both were disappointed. This child I proved, by cystoscopic examination and the finding of tabercle bacilli in the urine. to be suffering from a tuberculous cystitis secondary to a similar disease in one kidney.

CASE II.

D. G., aged 52, was sent to me at the hospital with a diagnosis of enlarged prostate and etone in the bladder. For the last nine months he had suffered with incressed frequency of micturition, pain at the end of the penis after the act, and often blood at the same time. His urine had been thick throughon that period and he had several times passed pieces of grit. His doctor had sounded him and thought that he felt a stone. Once he had quite a free attack of haematuria which lasted for a day, the blood being intimately mixed with the urine. His condition when I saw him was as follows: Frequency of micturition every hour and a half by day and four times at night; pain was of two kinds, a dull aching more or less constant pain above the pubes relieved by micturition, and a sharp stabbing pain at the end of the penis after emptying the bladder; he also complained of difficulty in starting and a loss of force in the stream, and he -more or less constantly passed a few drops of blood at the end of a clear urine.

Rectal examination proved to me that his prostate was not -enlarged, but I thought that there was some increased resistance on the left side of the bladder base. Cystoscopy showed an irregular, infiltrating, sessile growth, with raised edge situated on the left side of the base and posterior wall of the bladder, and surrounding the left ureteric opening. The surface of this growth was coarsely papillated and densely covered with phosphates, and this it was which accounted for the sensation of stone obtrined with the sound.

I need not multiply instances of this kind; but 2.8 a farther example let me take two diseases of tho kidneytaberculosis and stone. For the differential diagnosis of these diseases certain rules have been laid down. It is said that with stone the pain is severe, renal colic the rule, and haematuria free, all being increased by exercise and relieved by rest; bat if the pain is more of a dall ache, colic being absent, the haematuria slight, and both are unrelieved by rest, that you should diagnose tubercle. But how often in practice do we kee these actually reversed! A stone may exist in a kidney for years, particularly if embedded in its substance, without producing any symptoms noticed by the patient; on the other band, tubercle may cause the most typical abtacks of renal colic. The severity of the pain is no accurate guide, neither is the amount of the haematuria; the relation of both to exercise is, however, often a help, but is not to be relied on. I saw a boy a little time ago, 12 years of age, who had suffered on and off for five years with dull aching pain in his left loin, accompanied by the constant passage of thick urine. He was subject to exacerbations of pain about once a month, but the pain was never acute, and his parents had never noticed any blood in his urine: the microscope, however, showed both blood and pus. When the attacks were on they lasted day and night, and were not increased by exercise. On a priori grounds, therefore, we should bave been justified in diagnosing tubercle, but repeated examinations of his urine for tabercle bacilli proved negative, and the $x$ rays showed that he had a stone in that kidney, removal of which cured him.

Growth of the kidney may cause symptoms which are often indistinguishable from those of stone or tubercle.

\section{CASE III.}

W. P., aged 54, sent to me by his doctor, was suddenly seized four years previously with a sudden acute attack of pain in his right iliac fossa. radiating thence to the loin, and accompanied by vomiting. The attack lasted for eight hours, during which time he had to pass his urine every half-hour, but there was no blood in the urine at this time. He was free from any pain or other sign of disesse for eighteen months, when a similar attack occurred, but. this time accompanied by blood in the arine, which was intimately mixed ; the pain lasted eight hours arine, which was intimately mixed ; the pain lasted eight hours and the blood twenty-four hours. At the end of twelve months
he had another and exactly similar attack. During the three months before I saw him, and whilst he was under my observation, he had attacks every fortnight; the pain was chiefly in the loin, and acute while it lasted, was made worse by exercise, and usually occurred towards the end of the day, each attack being accompanied by a moderate amount of bleeding; but nothing more than I have seen in several cases of renal
stone. Just before he was about to be operated upon, however, stone. Just before he was about to be operated upon, however, a free haematuria occurred without pain, and continued for
several days, and this, together with the fact that the $x$-ray examination was negative, suggested to me that in all probability the cause of this man's symptoms was a growth, and not a stone. This was confirmed at the operation, when I removed a large growth involving the upper two-thirds of the kidney, which microscopically proved to be a carcinoma.

Then, again, such perversions of metabolism as lead to the excretion of calcium oxalate and uric acid crystals, or excess of phosphates in the urine, may give rise to attacks of renal pain, even accompanied by haematuria, and have in the past been the cause of many needless operations.

It will be clear then, I think, from these cases, that it is not by a study and analysis of the symptoms, however close, that we can arrive at a reliable ajiagnosis. It is only by making use of the several methods of examination at our command that we can elucidate them.

\section{B.-Due to Reflex Symptoms in other Parts of the Urinary Tract.}

I.

It is well known that diseases of the kidney may cause bladder symptoms, but it is not so well recognized that these secondarily induced symptoms may be so severe as to mask those of the primary disease in the kidney. In some cases the bladder irritation is purely refex; in others it is dne to the secretion of an unusually acrid urine by the diseased kidney; in otbers, again, it is due to an actual ulceration of the bladder mucous membrane resulting from the constant passage of infected urine from the kidney. This last condition is so constantly seen in tuberculosis of the kidney that it may almost be said to be the rule.

When such a transference of symptoms as this occurs it is almost certain that we shall be misled by them to diagnose a primary bladder affection unless a further examination is made, and of these cystoscopy is the quickest and the surest. In such diseases of the kidney as tuberculosis, pyelitis, and stone this transference of symptoms is by no means uncommon.

The following is a very extreme instance of a case of suppurative pyelitis of the kidney, producing and keeping up cystitis for twenty-two years, with recurrent forma. tion of stones in the bladder which had been repeatedly crushed, the underlying disease in the kidney not having been suspected.

A man, aged 54, since the year 1883 had constantly passed thick urine and had suffered from cystitis with the usual symptoms increased frequency of micturition and pain and blood after the act. Between the years 1883 and 1905 he had had twentythe act. Between the years 1883 and 1905 he had had five operations for stone in the bladder, litholapaxy twenty-one times, suprapubic cystctomy three times, and on one occasion he had his bladder drained through the perineum continuously for three months. When I first saw him, in November, 1905, he was suffering from one of his periodical six-monthly exacerbations of symptoms which told him that he had more stones in his bladder, and a cystoscopic examination showed two phospise of that viscus. It was not phatic calculi lying on the base of that viscus. It was iently possible, however, at that time to wash the bladder sufficiently clear of pus to make a satisfactory examination of the ureteric orifices. An attempt was made to crush these stones, but failed owing to the presence of a pouch in the bladder wall, into which they disappeared; they were therefore extracted through a perineal incision with a view to a subsequent continuous drainage. After a few weeks' drainage, the urine became some. what clearer, and, after prolonged washing, I cleared the blader sufficiently of pus to make a satisfactory cystoscopic examination, the instrument being introduced through the 
perineal wound. The following are the notes I made at the time: "There is a general cystitis, but no ulceration of the mucous membrane; the left ureteric orifice is widely dilated and rigid, with raised and scarred edges. As it was being watched a long, worm-like string of thick, putty-like pus was glowly extruded from its orifice and coiled up on the base of the bladder, filling several shallow sacculi ; no urine was emitted. The right ureteric orifice was small and bealthy in appearance, and jets of clear urine were being rapidly extruded as if from a hypertrophied kidney." Obviously, then, this man had a left kidney fall of pus, which was not only of no functional value to him, but was keeping up a cystitis with the formation of secondary phosphatic stones in his bladder. It was afterwards shown that he had a stone in his left kidney, which had probably existed for over twenty years, finally causing a complete disorganization of that organ, but without giving the patient any symptoms sufficiently severe to direct his attention to it.

Another equally instructive case is the following :

CaSE V.

A man aged 29 was sent to me suffering from increased frequency of micturition to twelve times by day and four to five times at night, accompanied by pain at the end of the penis after the act; the urine, which had frequently been tested by his doctor, always contained pus and occasionally blood. His history was that three months previously the attack had started with a rigor and frequent half-hourly micturition, but without blood at that time. On careful inquiry, however, I elicited the fact that he had for several years previously suffered on and off from slight lumbar pains, and that his urine had frequently been thick. Repeated soundings for stone had proved negative, and he had therefore been treatéd as a case of cystitis. There were no tubercle bacilli in the urine. I cystoscoped him during an attack of haematuria, and found that the right ureteric oriflce was dilated and redder than normal, and that every now and then jets of bright red blood were thrown out from it. The left orifice was healthy and exuding clear urine, and the specimen of urine drawn off from this kidney by the ureteral catheter was perfectly normal. I subsequently removed a stone from the right kidney.

It is by no means uncommon for a diseased kidney to cause reflex pain in the opposite organ, which may also be tender on palpation. When this bappens in a kidney which is compensatorily enlarged owing to advanced dieease of its fellow, one is particularly liable to be misled by this combination of facts to diagnose disease in what is a healthy organ, and if, as sometimes happens, the primarily disersed kidney has not caused any symptoms, the reflexly affected one is in a very precarious position if it happens to come under the care of a surgeon who is content to explore a kidney without making use of the various methods of functional diagnosis now at his command.

A much rarer reflex manifestation of kidney disease is pain in one testicle, and when this is the only symptom of which the patient complains it is not surprising that clinicians are led astray by it. The following case quoted by Newman is a good instance of this fallacy

The patient, aged 35, had been operated upon for varicocele, and removal of the left testicle had been suggested to him for the relief of severe pain in that organ. He consulted Dr. Newman, who, flnding that the testicle was bealthy, suggested cystoscopy, which was consented to, and be found as follows There was a very marked hyperaemia of the mucous membran around the left ureteric orifice, from which frequent small shoots of pale urine were escaping. The shoots from the right healthy ureter were about one a minute, whereas those from the left side were one every fifteen seconds. This, together with the irregularity in the size of the shoots, was taken as evidence of undre irritation of the left kidney. $X$-ray examination showed a small stone in the lower part of the left nreter, which was removed, after which the pain completely disappeared.

\section{II.}

Certain bladder diseases may cause reflex symptoms in the kidneys. This transference of symptoms from the bladder to the kidneys is much rarer than vice versa; in fact I have only known it to be misleading in growths of the bladder situated close to one or other ureteric orifice. Slight lumbar pains are freguent in obstructive conditions of the bladder, but are obviously secondary. However, in the cases to which I am now referring (three in number) the symptoms were-profuse attacks of haematuria accom penied by pain in one kidney, and in erch case a diagnosis of kidney bleeding had been made; in two the bleeding was thought to depend on a growth of the kidney, and in the third, owing to the severity of the pain, it was thought to be due to a stone. In one oase the patient was actually on the operating table ready for exploration of the kidney for a supposed growth, when an examination with the cystoscope revealed a growth of the bladder close to the ureteric oritice corresponding to the kidney in which he had the pain. In the third case, which I will briefly relate, a study of the patient's symptoms had led his doctor to make a diagnosis of stone in the kidney.

\section{Case vi,}

A man, aged 52 , had been seized six years before with a sudden acnte attack of pain in the left lumbar region accompanied by profuse haematuria, and on and off since then he bad been subject to attacks of bleeding with frequent kidney pain, which was always worse towards the end of the day. From these gymptoms his medical attendant thought that he had a stone in his kidney, and he was sent to me with a view to having it removed. On ciose cross-examination, however, I found out that he occasionally passed a spot of pure blood at the end of micturition, without any pain, and that he suffered from slightly increased frequency of micturition to every two hours by day. On cystoscopic examination, I found a small pedunculated smooth growth of the bladder above and to the inner side of the left ureteric orifice (the side in which he had the kidney pain) This growth, then, was the cause both of his baematnria and of the referred kidney pain, for his symptoms completely disppeared after I removed the growth of his bladder.

I have only noticed this referred kidney pain, unaccom. panied by bladder symptoms, in growths of the bladder situsted close to one of the ureteric orifices. Whether it is a truly reflex pain or is caused by the growth dragging on and obstructing the ureteral outlet, I am not at present quite convinced; but in each of the crses above quoted, so far as I could see, thare was no distortion of the ureteric orifice.

\section{C.-Due to the Absence of Symptoms pointing to the Locality of the Disease.}

In such cases as these the patient seeks advice for recurrent attacks of baematuria, or says that he constantly passes thick urine, which on examination proves to contain pus, otherwise he remains in perfect health. He is quite free from any symptoms from which conclasions can be drawn as to the part of the urinary tract from which the blood or pus is coming. Such cases may be most puzzling, yet it is in such cases that an early diagnosis is of the utmost importance, for in many, if we wait for the development of farther symptoms, it may be too late for successful treatment; the cystoscope is our only hope. This so-called symptomless haematuria is moderately common, and may have either a vesical or a renal source. Cystospopy has shown that growths of the bladder, especially when sitzated away from the sensitive trigone, may, and often do, exist for months without producing symptoms other than haematuria. This bleeding is often profuse and intimately mixed with the urine, and not characteristically distributed at the end of micturition. Symptomless haematuria of renal origin may occur in such diverse diseases as growths, tubercle, stone, and last, but by no means least, chronic granular nephritis. Let me impress upon you that this latter condition may give rise to profuse attacks of bleeding. It may be recognized, if suspected, by examining the urine for albumen and casts between the attacks of bleeding. The following is a case in point :

\section{CASE VII.}

A few weeks ago I was asked bv her doctor to see a lady who had been subject to profuse attacks of haematuria for ten years. The bleeding used to come on without any warning, was generally profuse at tirst. and gradually subsided in the course of a week or ten days. This was absolutely the only symptom, and there was nothing in the history to enable us to decide whether the blood was coming from the bladder or the kidneys. She was unable to say if the blood was evenly distributed throughout urination or not, but from the large amount present it probably was. After washing the bladder as clear as possible of blood, I introduced the cystoscope, and found an extremely widespread growth, covering almost the whole surface.of the bladder. In parts this growth still had the appearance of an bladder. In parts this growth still had the appearance of an innocent papilloma, but for the most part it was sessile and
infiltrating the mucous membrane, and had undoubtedly become malignant.

Pyuria without other symptoms is rarer, and usually denotes some affection of the kidney. It may result from a simple pyelitis, tuberculosis, or stone. The fact that pus in the urine may be the only sign of a chronic prostatitis, the remains of an old attack of gonorrhoea, must, however, not be lost sight of. I have found pus threads present in the urine as long as ten years after the acute attack had subsided, the patient believing himself long since cured. 
Methods of Accoratr Diagnosis.

\section{The Cystoscope in the Differential Diagnosis of} Bladder Diseases.

Accuracy in diagnosis can only be attained by a careful and methodical use of all the methods of investigation at our command; no one of them should be omitted, each has its appointed place, and each is more or less dependent on the others for its success.

Cystoscopy is that which gives the most accurate and extensive information. With the perfecting of the cystoscope by Nitze in 1887 the foundation of modern urinary surgery may be said to have been laid. It completely revolutionized our ideas and enabled us to study the pathology of disease in the living. subject. The result has been seen in the enormous strides which this branch of surgery has made in the last few years, the only parallel to which is to be found in the sudden advance in our knowledge of diseases of the eje that followed the invention of the ophthalmoscope.

Various modifications and extensions of this instrument have been made, the most important of which is the catheterizing cystoscope, which renders possible the passage of catheters up the ureters from the bladder, and the direct collection of urine from each kidney separately. There are many other modifications, such as operating and photographing cystoscopes.

Tubercalosis, stone, simple cystitis, growths, and foreign bodies, although they may produce almost identical symptoms, can readily be differentiated by the cystoscope, for each gives a characteristic picture to the experienced eye. The cystoscope also affords invaluable data in treatment and prognosis. Not only is it easy to see stones in the bladder, bat their number, size, probable composition, the accompanying state of the bladder and whether or not it is pouched, all important points in deciding whether we shall crush the stones by litholapaxy or remove them through an open incision, can be ascertained.

In growths of the bladder we can determine their size and extent, their innocency or malignancy, their situation, whether on the anterior wall of the bladder, where they can be easily and safely resected, or growing from the base close to or surrounding the openings of the ureters, in which case their removal might mean a serious and risky operation and necessitate transplantation of the ureters. Taberculosis, simple ulceration, and cystitis each gives its its own picture.

The Cystoscope in the Localization of Disease.

The normal ureteric openings are oblique slits in the bladder mucous membrane with pouting lips, situated on a raised bar at the upper end of the trigone. If one watches them steadily one notices that from time to time the bar to the outer side of them swells up and then suddenly the lips separate and a stream of urine is projected into the bladder, where it diffuses in the lotion like a drop of glycerine in water.

By observing the appearance of these orifices, whether they are inflamed, oedematous, ulcerated, gaping, fixed, or movable, and by counting the number of times the urine spurts out from thein in a minute (frequent emissions point to either an irritated or a hypertrophied kidney on that side), and by carefully watehing the urine for blood or pus as it diffuses in the clear lotion with which the bladder is filled, we may draw inferences (the accuracy of which increases with one's experience) as to the state of the corresponding kidney.

Then again, a fair knowledge of the working value of the kidneys may be obtained by watching the ureteric orifices in the bladder through the cystoscope and noticing bow soon and in what quantity methylene blue first appears and continues to be secreted in the urine after its injection into the muscles of the buttock (chromo-cystoscopy). The blue should appear within fifteen minutes, and any delay beyond this time suggests some interference, with the function of that kidney. This method is chiefly of value in those cases in which catheterization of the ureters and the direct collection of the urine from the kidneys is not available.

Those cases included under our third group of difficaltic $B$, in which either blood or pus is passed without any accompanying symptoms to guide us to its origin, are rapidly cleared up by simple inspection with the cystoscope. If it originates in the bladder its source can hardly escepe our notice; if in the kidneys, blood or pus may be seen coming out of one or other ureteric orifice.

By cystoscopy, then, diseases which it is difficult to localize owing either to referred symptoms or to the absence of symptoms pointing to the diseased area, can be easily and accurately localized by a simple examination without catting, without pain, and with only a minimum amount of inconvenience under local cocaing anaesthesia. What an advance on the old method of exploratory operation!

\section{Cystoscopy combined with Catheterization of the} Ureters.

Catheterization of the ureters is rendered possible by an addition to the ordinary cystoscope of a channel for the passage of a catheter and a movable flange by means of which the point of the catheter may be altered in direction, and so guided into the mouth of the ureter.

This method enables us to draw off the urine from the kidneys separately, and thus gives us a direct indication as to their bealth or otherwise. It enables us to say definitely whether a kidney which we suspect to be diseased is so or not, and thus places in our hands an infallible way of determining whether deductions drawn from an inspection of the ureteric orifices and their Effluxes were correct. It may be made use of also for sounding the ureters in a case of suspected stone, special metal-tipped bougies being made for this object.

But the greatest value of ureteral catheterization lies in the power it gives us of estimating the functional value of the kidneys.

We may get some idea of this by estimating the quantity of urea excreted by a kidney compared with that secreted by its fellow, though this is for several reasons not always reliable, and we shall gain more trustworthy information by comparing the activity of the two kidneys in excreting methylene blue after its injection into the muscles of the buttock, or by comparing the amount of sugar secreted by each kidney after the injection of phloridzin (phloridzin diabetes). Both of these processes depend on the activity of the renal epithelium, so that we have in them methods by means of which we can estimate directly the amount of work which each kidney is doing.

The value of this knowledge lies in the power it gives the surgeon of estimating the working value of the other kidney when he is about to remove or seriously interfere with its fellow. Previously a surgeon was obliged to start an operation on a kidney knowing full well that the opposite organ might be more diseased than the one he was attacking, or even absent altogether; in either of which cases his patient would die of uraemia.

That this fear is no myth can be proved by looking up the statistics of kidney operations, especially nephrectomy, in any large hospital. The mortality of nephrectomy, even in the hands of surgeons with world-wide reputations, was until recently as high as 20 or 33 per cent. Israel reports that in his last series of nephrectomies-97 in number-he lost 9 out of 47 before he employed ureteral catheterization, but since employing this method systematically he has only lost 2 out of his last 50 cases - that is, he has reduced his mortality from 19 to 4 per cent. The drawings taken from specimens collected from the post-mortem room during the last twelve months illustrate the point very well. Some of them are completely disorganized kidneys which became so without their late owners' knowledge, and were only found by chance during the examination after death. They will serve to impress upon you the fact that it is by no means uncommon for a kidney to reach an advanced stage of disease without producing symptoms. In this lies the danger of kidney surgery.

Fig. 1 shows a kidney so completely filled with a large branching stone that the remaining kidney parenchyma measures little more than a quarter of an inch in thick. ness, and is so degenerated from pressure and inflamma. tion that it could not possibly have been functionally of much use. Yet it was found accidentally in the course of a post-mortem examination, and, although it must have existed for years, had caused no symptoms during life.

Fig. 2 shows a maldeveloped and lobulated kidney not more than one.fourth the size of the normal organ, the pelvis of which is filled with and blocked by a large stone. The patient in whom this was found at the necropey 
had suffered during life from acute symptoms in the ipposite kidney; which was so disorganized from the results of a large stone that it was removed. This kidney was thought to be healthy because it had caused no symptoms. The patient died of suppression of urine and uraemia. It is by no means uncommon for stones to be present in both kidneys at the same time, and the absence of symptoms is no certain indica. tion that a kidney is healthy.

Fig. 3 shows a kidney com. pletely disorganized by caseous tabercle. It, again, was found post mortem in a woman who had died from some disesse entirely unconnected with her kidneys, and who had never suffered from any symptoms referable to those organs.

Then, again, it is by no means uncommon to find kid. neys that have never reached their full development. I)aring the last eighteen months I have come across no fewer than five instances of this kind, varying from complete absence of any trace of one kidney in one case to organs one-fourth the size of the normal. The kidney shown in Fig. 4 is no larger than a walnut, and consists mostly of fat. In such cases, and also when one kidney is in a state of advanced disease, the opposite kidney is enlarged to compensate for the small amount of secreting tissue in the other; and if for any reason it becomes necessary to explore the hypertrophied organ, its very size may lead to its removal and the death of the patient.

Since kidney disease is frequently bilateral, especially in stone and tubercle, and since a kidney may be the subject of adranced disesse without symptoms sufficiently

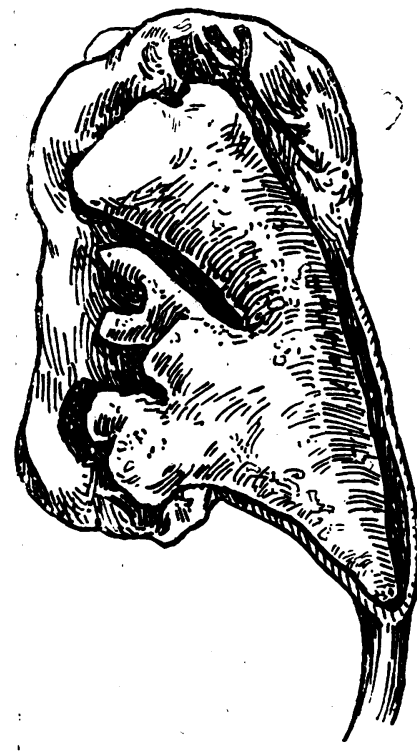

Fig. 2.-Shows a maldeveloped lobulated kidney with a large stone completely filling and blocking the pelvis. It had caused no symptoms during life and was therefore thought to be healthy the opposite kidney being removed with disas trous consequences. severe to call the patient's attention to it, it is obviously our daty to estimate the functional capacity of the other kidney before operating on one. This can only be satisfactorily done by means of catheterization of the ureters.

I have purposely omitted any description of segregation of the urine by means of the urine separator, for the reasons that it is unreliable, very painful to the patient, and ex. tremely liable to cause bleeding. Unless used in conjunction with cystoscopic examination it is often absolutely misleading.

3. Radiography of the Kidneys and Ureters.

As experience with this method of investiga. tion has increased and as the instruments employed have been im. proved the results have become increasingly more reliable year by year. Some operators claim to give a correct diagnosis by this means in as large a proportion of cases as 95 per cent. This is certainly more sanguine than is warranted by $\mathrm{my}$ own experience. The introduction of enormously powerful coils and tubes, with the correspondingly diminished time of exposure necessary to obtain a good negative, has undoubtedly increased the reliability of this method of exa. mination, but it still lacks any thing approaching certainty. One may be misled by it into committing two errors of diagnosis: (a) Errors of omission, in that we may fail to obtain a shadow of a stone when one is present; and (b) errors of commission, when we mistake for stones shadows on the negative which are not due to stones at all.

The first fallacy-that in which, although $a$ stone is present in the kidneys or ureters, no shadow appears on the negative-may be due either to the composition of the stone being such that the rays pass through it too easily (uric acid is the least opaque, calcium oxalate most opaque, and the phosphates come in between), or the stone may' be so small that its shadow is lost in that of other objects.

The second fallacy depends on shadows thrown by objects opaque to the rays other than stones, and which, although they are not situated in the kidneys or ureters, yet throw their shadows in what we judge to be the line of those structures. Such things as calcified mesenteric glands, concretions in the appendix, and hardened faeces, may be mistaken for stones in the kidney; and calcified phleboliths in the uterine or prostatic veins may throw shadows which will be mistaken for stones in the ureter.

We overcome these difficulties by first of all passing up the ureters bougies which are opaque to the rays or contain metal stylets, and then taking a radiograph. The shadow of the bougie will tell us the line of t h $\theta$ ureter and pelvis of the kidney, and unless the shadows on the plate are in that line it is obvious that they cannot be in the ureter.

Despite these obvious sources of fallacy, radiography has helped the urinary sur-

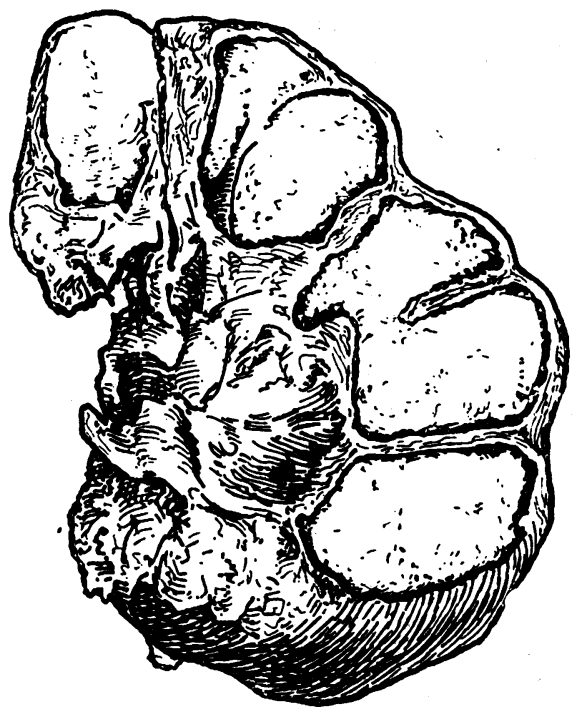

Fig. 3. - Shows a kidney completely disorganized by caseous tubercle which had caused no symptome during life.

siderably, and should always be made use of in a routine examination of the kidney. It should always include both kidneys and the whole length of both ureters, for we know that stones may exist in both kidneys, although the symptoms are one-sided; and stones in the ureter often cause symptoms indistinguishable from those of stones in the kidney. A good skiagram should show the outline of the psoas muscle and the shadow of the kidney, and as faeces throw shadows, it is essential that 
the bowels should be very thoroughly emptied before. hand.

\section{Other Methods of Examination.}

These investigations-cystoscopy and its adjuncts and radiography - can only be carried out by those who have the necessary instruments and the experience to use them. There are other methods of investigation, however, from which much may be learnt that is indispensable in the interpretation of urinary disease. One of the most impor tant of these is the chemical and microscopical $\in$ Xamination of the urine. The significance of the constant or periodical presence of small quantities of blood, pos, or casts in the urine cannot be exaggerated. A naked.ege examination of the urine for blood or pus is not sufficient; microscopical search of the centrifugalized urine must be insisted on.

The bacteriology of the urine, especially the search for tubercle bacilli, must be carried out very thoroughly and exhaustively, and repeated several times if negative and tuberculosis be suspected. Care must be taken not to mistake the smegma bacillus for that of tubercle. It is an acid and often spirit-fast bacillus, which in appearance and staining reactions almost exactly resembles the tabercle bacillas. It enters the urine by contamination frow the urethra and foreskin or labia during micturition. It may be eliminated, therefore, by examining only catheterized specimens. It is by no means uncommon to

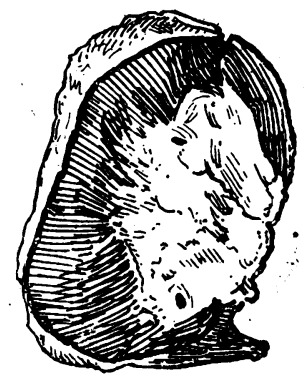

Fig. 4-A full size drawing of a maldeveloped kianey. This is one of five found in the post-morte $m$ ruon during the last eighteen months.

find it in urines, especially of females; and to condemn a patient to a diagnosis of urinary tuberculosis because he happens to have smegma bacilli in his urine would be an awful mistake and one which might have far-reaching consequences. In women I always insist on a catheterized specimen, but in men in whom the passage of a catheter is a more serious undertaking. I find that specimens obtained alter thorough cleansing of the glans and foreskin, with rejection of the first few ounces of urine passed, and the collection of the remainder without contact with the fore skin, are reliable.

The tuberculin tests, Calmette's conjunctival reaction, and von Pirquet's skin reaction, are of negative value only, for it must be borne in mind that tuberculosis of the urinary organs is never the primary deposit in the body : there is always some otber focus from which they become infected via the blood stream.

Such methods of examination as sounding and washing out the bladder are not so reliable as cystoscopy, and should therefore only be employed in conjunction with it, or when it is not available.

One method of examination yet remains to be mentioned: it is I am afraid a much neglected and by no means pleasant one, but it is one from which very often conclusive evidence may be obtained-I refer to rectal ex. amination. With a finger in the rectum, the prostate, seminal vesicles, lower end of the ureter, and the base of the bladder, may be thoroughly examined, and from in formation thus obtained I have often been able to clear up what were otherwise puzzling cases.

THE Jessop Hospital for Women, Shéffleld, will receive $£ 2,000$ under the. will of the late Mr. J. E. Cutler of that city.

THE Yorkshire Automobile Club members' competition for four-cylinder touring cars brought together a good number of 15.h.p. vehicles. The order of flnish in the opening heat was Sunbeam, Argyll, Talbot, Arrol-Johnston. The Argyll made its first appearance in a race. The car was a standard 15 h.p., and weighed fully a ton.

\section{ON THE EAREY DIAGNOSIS AND TREATMENT} OF TUBERCULOUS KIDNEY.*

By ANDREW FULLERTON, M.D., F.R C.S.,

ASSISTANT SURGEON TO THE BELFAST HOSPITAL FOR SICK CHILDREN AND THE ROYAL VICTORIA HOBPITAL, BELFAST.

OUT of a recent feries of 400 cases of all sorts of bladder and renal complaints requiring the use of the cystoscope for diagnosis of which I have more or less extensive notes, 24-that is, 6 per cent.-were cases of tuberculous kidney, and as most of them have been seen in the course of private practice, enabling me to follow up their subsequent history, it has occurred to me that an analysis of them might be of some interest to the members of this society. In 13 of these the diagnosis was confirmed by operation, 9 having been operated on by myself and 4 by other surgeons. In a few, other tuberculous foci were found in other parts of the bods-for example, lymphatic glands, epididymis, testicle, prostate, or lungs-but these associated lesions were entirely overshadowed by the renal or vesical condition. In the large majority the bladder was secondarily involved. I may remark, in passing, that I have not been able to satisfy myself that 1 have set seen tuberculous disease limited to the latter organ. In most cases the kidney has been involved. and in the remainder the epididy mis, testis, or prostate. From my own small experience, I believe that the most frequent cause of tubercle of the bladder is descending infection from the kidney.

Sex.

Eleven cases occurred in the male sex and 13 in the female. This shows a slight preponderance in the female, which accords with the general experience of genitourinary $\&$ urgeons.

$$
\text { Age. }
$$

The youngest patient was a boy aged 11 years. The case was an undoubted one, tubercle bacilli having been found in the urine, with enlargement of the left kidney, and characteristic ulcers in the bladder, chicfly on the same side. Another case was that of a girl aged 12 jeare. One was a boy, aged 17, who had, in addition, signs of early phthisis at the apex of the right lung. Eight occurred between the ages of 20 and 30, eight between the ages of 30 and 40 , and three between the ages of 40 and 50 . The general $\mathrm{experience}$ of surgeons is that the most susceptible age is between 20 and 40 , and this is well borne out by the statistics I have just quoted, nearly 70 per cent. of $\mathbf{m y}$ cases having been met with at this period of life.

\section{Family History.}

In 8 cases I was able to elicit a distinct history of tubercle in the immediate relations. In all but one of the remainder a family history of all forms of tabercle was denied. In one case I failed to find any note on this point. In about 33 per cent, therefore, there was a distinct family history of tubercle. In one case with, however, a bistory of pulmonary tubercle on the maternal side, the onset of the disease was attributed to the patient baving had in her house for a year a parlourmaid in an advanced state of pulmonary phthisis.

\section{Side Affected.}

In 11 cases the right kidney was affected, as revealed by clinical methods; in 11 the left; in 1 both kidneys were obviously diseased, and in 1 the second kidney was suspected.

I am aware that it is impossible to say that a kidney is unaffected with tabercle even if the urine coming from its ureter shows no abnormality. Tubercles may be present in the kidney and give no sign of their presence. I shall return to this point at a later stage.

Presence of Tubercle Bacilli in the Urine.

I regret that the search for tubercle bacilli in the urine of these patients was not carried out so frequently or so persistently as I could have wished. They were found in 11 cases. In some of the remainder the diagnosis sfemed so obvious that the search was not persisted in. I am satisfied that a prolonged search on many successive occasions is often necessary before the bacillus is found.

\footnotetext{
* Read at a meeting of the Ulster Medical Society.
} 